American Journal of Economics and Business Administration 2 (2): 189-193, 2010

ISSN 1945-5488

(C) 2010 Science Publications

\title{
The Innovative Technique at Thomson
}

\author{
${ }^{1}$ Raveesh Agarwal, ${ }^{1}$ Mona Chaudhary and ${ }^{2}$ Suryakant Dixit \\ ${ }^{1}$ Department of Management, Institute of Management Education, Sahibabad, Ghaziabad, India \\ ${ }^{2}$ Department of Human Resource, Thomson Press India Ltd. Okhla, New Delhi, India
}

\begin{abstract}
Problem statement: As we continue to ride out of the current economic recession, employee engagement has become a critical business issue for the organization. It is tough time for Thomson Press to enhance its position as leader in printing industry and stay ahead of competition. Key challenges include identifying the areas of improvement and engaging each and every employee of the organization at an individual level so that everyone benefits-the business, the environment and the workforce. Approach: In order to meet the challenges and to sustain its leadership in the market, Thomson has taken a new initiative "Vaarta-an Employee Engagement survey". To ensure the objectivity of this process and maintain the confidentiality of the responses, Thomson appointed "hrcraft business consultancy", an external agency which specializes in conducting such surveys for many reputed organizations. Results: The survey identified areas of strength and weakness of the organization to assess levels of employee engagement and set new priorities for its employees and customer services. It helps officers and managers to gain useful insights, on how their team members engage with their team and then to take specific actions to address areas of concern. Equally, senior leadership will get insights on application of policy of the organization to enhance their motivation and drive. Conclusion: The objective of writing this case is to gain insight into the human resource practices being adopted at Thomson Press. This case described a new initiative-"Vaarta", which will facilitate the organization through engagement of its employees into a high performance workforce during recession period. This will make a significant contribution to improvements in levels of customer satisfaction and business growth. It will help individual officers and managers in identifying specific and positive action steps towards engaging their team and thereby, enhancing and sustaining business performance.
\end{abstract}

Key words: Employee engagement, recession, Vaarta

\section{INTRODUCTION}

As a leader in the competitive printing industry, Thomson believes its associates are the greatest asset and knows that its success rests upon engaging those associates. With a vision to maintain and to be acknowledged leader in printing through consistent improvement in quality, Thomson Press India Ltd. was established in 1967. The main thrust of the company was printing of children's book for export and the distribution of publications of a large number of overseas publishers. Now Thomson Press not only prints number of prestigious magazines for various publishing houses but also prints high quality commercial POS items and books for the domestic and export markets. Its product range covers designing, copy editing, typesetting, high quality scanning and image manipulation, sheet fed offset printing, heat-set and cold-set web offset printing, automated binding, finishing, distribution and mailing services that meet international standards and varied requirements of its esteemed customers. It is one of the largest integrated data processing and printing service provider in South Asia having mission to recognize the customer's right to quality, services, timely delivery and cost, to ensure maximum satisfaction to the clients, to continue to maintain ethical practices, legal, social, personal conscience framework, to encourage individual growth to fullest potential, to maintain high degree of efficiency and attain international standards and quality through people and technology.

Thomson Press has been in international business for over two decades and in a focused manner for last 15 years. In line with becoming global player, Thomson has made substantial investments. Essential facilities and equipment in the plant make it a cost efficient

Corresponding Author: Raveesh Agarwal, Department of Management, Institute of Management Education, Sahibabad, Ghaziabad, India Tel: 9910421009 
solution provider that match the best in the world and acknowledged by customers abroad. Its unique one-stop structure and unique product quality has always given it an edge over others. It pledges to achieve customer satisfaction by continual improvement in its processes and excellence in quality. Standard has been set as per the ISO 9001-2000 international quality system and has been certified from BSI India Pvt. Ltd to provide quality assurance. The standard is being revised from time to time whenever there is some improvement or modification in the system. Periodical audit of the system standard is being conducted to check the compliance of the standard. Every customer complaint is being thoroughly investigated by the company for its origin and reason. Necessary corrective and preventive action is being taken in consultation with the concerned departments.

Thomson understands the importance of its employees and customer satisfaction. It is an organization's employees who influence the behavior and attitudes of customers and it is customers who drive an organization's profitability through the purchase and use of its products. One of it core values is if we take care of our employees, they will take care of our customers (Treacy, 2004). It is nurturing and educating the youth into technocrats through Thomson School of Printing. The 'training school' was started in 1995 with an aim to produce printing professionals to meet requirements of quality manpower. Thomson conducts regular in-house training programs for technological improvement; motivate their workforce for excellent standards in work procedures through Kaizen to deploying specific, measurable and time-bound objectives in all processes in various functions. Thomson has taken great care to build and maintain a company culture which values and respects staff as individuals, giving everyone a sense of involvement in the process.

Thomson's senior managers operate an open door policy and understand that an organization's best source of competitive advantage is its people. Strategies, business models, products and services can all be copied by competitors. Talented people, by contrast, can not be duplicated and will always set the organization apart. Achieving a competitive advantage through people requires that organization succeed in attracting and retaining talent. In Thomson's view, engaging with employees in such an open and transparent manner maintains employee retention at high levels. The average worker stays with the company for a lifetime. Like most other organizations, Thomson was well aware that a drop in engagement at the front line is likely to have an impact on customer service. So the company has taken number of initiatives to place new performance management systems, greater learning and development opportunities, new management development programmes, employee recognition schemes and flexible working practices to motivate employees and build loyalty. Employees are offered challenging work and the autonomy and flexibility to improve the services they deliver. Staff is trusted to manage their time effectively. However, Thomson ensures that all staff understands the organization's values and standards and that they have clarity on what is expected of them. Staff is given the information they need to do their jobs well. The results are found satisfactory. Engagement levels and profitability have improved very significantly and it has successfully completed huge business integration.

Since the business environment requires keeping improving day by day to face many challenges, inevitably, challenges have had to be faced. The challenges occurred in 2008-09 due to recession all over the world. The Thomson management agreed that it was clearly time for change and that the only effective way to make that work was by getting everyone in the organization involved. The key was to engage with staff and to ensure that all staff policies, including those surrounding performance management, were seen to be fair and consistently applied to all. Workshops were held where every team and each team leader was given the opportunity to express their views about how improvements could be made and how teams should be managed. Employee engagement was a new way of working that was endorsed by the staff. Employee engagement approaches can help companies and organizations deal with the challenges of recession because by establishing trust, they can unlock more of the knowledge and commitment of individual employees (Vazirani, 2007).

As we continue to ride out of the current economic recession, employee engagement has become a critical business issue for the organization. Bottom-line effects are disenchanted staff and decreased productivity. It is tough time for the company to enhance its position as leader in printing industry and stay ahead of competition. It is clear that with large cost savings to be made in the organization, there is an ongoing challenge to motivate people, even though some tough funding decisions may have to be made. Continuing to deliver good services, in changing times with less money is a concern, which means that the clear messages, open culture and strong leadership must remain a high priority (Bono and Judge, 2003). However, its successful approach to sharing the responsibility for engagement across leadership, business operations, 
human resources, communications and marketing teams, is something Thomson is extremely proud of and believe that it will pay real dividend in tough times. Despite the improvements facilitated by Thomson, it recognizes that there is still more to do. Key challenges include identifying the areas of improvement and engaging each and every employee of the organization at an individual level in this recessionary environment along with taking innovative and inclusive action so that everyone benefits-the business, the environment and the workforce. At the end of each working day a high level of employee engagement can be sustained (Bernthal and Wellins, 2001). The organization identified three areas for improvement: customer satisfaction, business performance and organizational culture to meet a number of challenges in its market, including changing customer needs. The company began by addressing organizational culture, recognizing the importance of ensuring all of its employees were engaged. The organization believes that high levels of employee engagement would support its mission to be recognized both internally and externally as an outstanding, responsible employer and continue to be industry leader.

In order to realize these objectives, Thomson embarked on new initiative-Vaarta-an Employee engagement survey which facilitates the organization to sustain its leadership through engagement of its employees into a high performance workforce during recession period. Engaged employees have a greater sense of well-being than those who are less engaged. They are more likely to be satisfied with their work, less likely to be sick and less likely to leave the organization. The mammoth task involved several months of study to design a perfect framework for employee engagement programme. This led to planning, design and development of Vaarta communicating core elements and a set of core competencies. The objective of Vaarta is to create a forum for the employees to give systematic feedback on how "immediate officer/manager" can sustain and enhance passion and commitment to the organization. The Vaarta survey is specially designed to help officers and managers to gain useful insights, on how their team members are being impacted by the way they engage with their team and then to take specific actions to address areas of concern, as well as to sustain the strengths of employee. Equally, senior leadership will get insights on application of policy of the organization to enhance their motivation and drive. It covers all employees in all departments of the organization.
"One size does not fit all" when it comes to the steps that employers could take with regard to employee engagement, Thomson might want to focus on specific drivers of engagement for employees in particular age/generational groups and different drivers for those in other groups. To ensure the objectivity of this process and maintain the confidentiality of the responses, Thomson appointed "hrcraft business consultancy", an external agency which specializes in conducting such surveys and implementation plans for reputed organizations such as Pespsico, Escorts, IndiGo Airlines and Ceat Tyres. Thomson chooses hrcraft because of its track record in helping staff at all levels understand and get behind new initiatives which helps companies gain insights into the views of their critical stakeholders-employees, senior leaders and customersand use these insights to shape people strategies and programs that align organizational culture, employee behavior, customer behavior and financial results. hrcraft administers an independent survey for Thomson and no Thomson Press employee was involved in conducting Vaarta. It allows staff to be more open and honest than in an in-house survey. Each employee of Thomson was given Vaarta questionnaire, informational brochure and newsletter which included stories on the program by hrcraft. The Vaarta survey comprises of 58 questions which cover many recognized drivers of commitment across five dimensions addressing areas which are impacted by "immediate officer/manager" as well as by the company policy and rules. Employees respond to these questions with "Strongly Disagree", "Disagree", "Neither Agree nor Disagree", "Agree", "Strongly Agree".

The surveys supported the drive to improve business strength and optimize levels of customer service by enabling the organization to assess its work culture, assess levels of employee engagement, identify areas of strength and weakness, set new priorities for its people strategy and programmes. The main drivers of the Vaarta are age, health, training and development opportunities, access to the flexibility, clarity of roles, supervisor support, organizational culture and organization communication. The Vaarta also highlight the issues like expectations from work, regular feedback from customers, expression of thoughts without fear, performance management system, balance between work and personal life and confidential treatment of feedback. This employee survey covers all aspects of employee life including coworker relationships, promotion opportunities, publicly recognition of contribution, fairly treatment by managers, respect of new ideas and involvement in decision making. 


\section{Specific objectives of Vaarta:}

- To find out more effective performance management system that is the cornerstone of engagement--from goal-setting to reward, recognition and incentive programs

- To ensure that performance was evaluated consistently and fairly

- To find out the accountability of managers for their employees in the organization

- To empower staff to take a greater responsibility for their own performance and development

- To create a sense of connectedness through communities of practice, cross functional teams and by creating common work areas

- To recognize employees for their suggestions, employ group brainstorming and utilize group members to enhance the feeling of connectedness

- To create the sense of engagement that individuals are a part of a greater entity

- To rank cross-functional teams and councils as the most effective vehicle which help employees to understand how their team and business unit's efforts contribute to corporate performance

Surya (one of the author of this study) a human resources specialist who at the time of starting the survey in July-August 2009 was Thomson's human resource manager and his team was concerned about the feedback. Surya believes that Human resource department can't manufacture engagement, but it has a key role in helping to develop the kind of organizational culture where engagement can thrive and ensuring that managers have the skills to make engagement a reality. It's about a shared way of working-a culture-that celebrates success, communicates effectively and explains the action plans (Conger, 1992). Although all the employees of Thomson are intrinsically linked, work together to lift performance and have ownership of the process, a piecemeal approach would have ruined this initiative. It was essential to get everyone behind Vaarta from the beginning. It is something what Thomson was trying to achieve with this initiative. It's simple and involving formal structure coupled with relevant content, enabled participants to really explore their own views on many area-rather than have another set of 'How to Manage' rules and regulations to swallow. The complete process of Vaarta is designed to encourage feedback, thus enabling Thomson to use the views of all those involved in this process. This has meant that each employee has clearly understood the rationale behind Vaarta even though this was difficult for all employees and in some cases, reduced attention by certain employees. Separately, Surya and his team also needed to secure the active participation of all employees in this survey to ensure that the business was 'right-sized' and 'right-costed' in light of the more difficult market conditions with focus on employee recognition in the organization. They know that the ultimate goal of Vaarta is to obtain honest feedback from all participants that can be translated into action to achieve optimal organizational growth and development. To achieve this, participants must be confident in the process and the organization must trust the results. Participants need to know that the organization has a genuine interest in listening to their candid opinions and they must be assured that their input is kept confidential (Conger and Kanugo, 1988). Another cause for concern was the lack of support people felt from their team members. Other challenges in front of his team were to educate beneficiaries on the importance of employee engagement survey, motivate beneficiaries to give true response for Vaarta to form a very good relationship with seniors and their team members. Since attitudes to senior managers are often regarded as quite negative by most of the employees in general, they encountered challenges in administration and implementation. The so-called 'death of deference' has impacted on the employer-employee relationship. The young generation has high expectations about what work will offer them in terms of self-fulfillment. However these higher expectations are not limited to one particular demographic. Increasingly employees expect to be treated as human beings with rights and responsibilities. For a high quality of working life it doesn't matter so much what the business is but how the people in that business behave (Hoover, 2005). In order for the participants to willingly engage in the employee survey process, Surya and his team demonstrated sincere plans to engaging the hearts and minds of employees at all levels to incorporate the honest feedback.

This is widely regarded in Thomson as a successful employee engagement exercise during the most difficult trading environment that the company has ever seen. Vaarta is a real achievement for Thompson which shows that there's something real going on as 'Thompson invests in people' mantra. It's about fairness, treating people as individuals, about giving individual sense of belongingness to Thomson. Thomson understands that Vaarta is a process not an event and simply doing a survey and publishing the results is not the same as an engagement strategy for an organization. The engagement strategy is a catalyst for re-building trust and confidence between individuals, their line managers and the organization (May, 2004). The most important thing is to arrive at a shared definition in the context of the business and translate it into action plan. An engaged employee is aware of the business context and works with colleagues to improve performance within the job for the benefit of the 
organization. Thomson believes that by gathering and analyzing engagement data, they will be able to pinpoint exactly where their imperfections can be found. Because the program is so new, reliable outcome data is not yet available. In a few months, Thomson Press expects that it will get feedback from hrcraft and employee feedback will be positive. The way "hrcraft" has communicated and administered Vaarta, Thomson opines that it is easy to understand, is straightforward and is actionable. Analysis of the survey results will provide insights that will enable Thomson to focus its people strategy on delivering the key objectives of its business transformation. This will make a significant contribution to improvements in levels of customer satisfaction and business growth. It will help individual officers and managers in identifying specific and positive action steps towards engaging their team and thereby, enhancing and sustaining business performance.

Since it is important to act quickly on survey results so that employees will know that senior management is committed to making positive change and action will occur while it is still relevant. If a company waits a year to take action, by that time some employee perceptions and attitudes are bound to have changed and thus the intervention will not be as effective as it would have been had it occurred within weeks of obtaining the survey results.

\section{Several issues are open for discussion:}

- Can Vaarta be considered an ideally structured exercise towards employee engagement?

- $\quad$ Are there pre-requites to make it more meaningful?

- What should Thomson do once the survey results are known?

- Will the transparent publicity create complexes in some sections of employees?

\section{CONCLUSION}

Employee Engagement is the buzz word term in corporate world. Engagement is all about getting employees to "give it their all." It is a positive attitude held by the employees towards the organization and its values. The objective of writing this case was to gain insight into the human resource practices being adopted at Thomson Press. This case described a new initiative"Vaarta", which will facilitate the organization through engagement of its employees into a high performance workforce during recession period. This will make a significant contribution to improvements in levels of customer satisfaction and business growth. It will help individual officers and managers in identifying specific and positive action steps towards engaging their team and thereby, enhancing and sustaining business performance. Thus we can conclude that maintaining employee engagement lies in the hands of an organization and requires a perfect blend of time, effort, commitment and investment to craft a successful endeavor. It would actively promote effective management leadership, systems and human resources practices to ensure enterprises are well placed to meet the challenges of operating in a competitive global environment'.

\section{REFERENCES}

Bernthal, P.R. and R.S. Wellins, 2001. Retaining Talent: A Benchmarking Study. Development Dimensions International, Pittsburgh, PA. http://www.ddiworld.com/pdf/ddi_MeasuringEmpl oyeeEngagement_wp.pdf

Bono, J.E. and T.A. Judge, 2003. Self-concordance at work: Toward understanding the motivational effects of transformational leaders. Acad. Manage. J., 46: 554-571. http://www.corporateheart.com/pdf/SelfConcordan ce\%20at\%20Work\%20Motivational2003.pdf

Conger, J.A., 1992. Learning to lead: The art of transforming managers into leaders. Jossey-Bass, San Francisco.

http://www.saycocorporativo.com/saycoUK/BIJ/jo urnal/Vol No1/Review_2.pdf

Conger, J.A. and R. Kanugo, 1988. The empowerment process: Integrating theory and practice. Acad. Manage. $\quad$ Rev., 13: 471-482. http://www.jstor.org/pss/258093

Hoover, G., 2005. Maintaining employee engagement when communicating difficult issues. Communication World. http://www.highbeam.com/doc/1G1-138060006.html

May, E.L., 2004. Are people your priority? How to engage your work force. Healthcare Executive. http://resources.greatplacetowork.com/article/pdf/h e_ja04_priority.pdf

Treacy, M., 2004. Employee engagement higher at double digit growth companies. Hewitt Associates. DDGEngagementHi04/01Rsjg4/04, http://www.hewittassociates.com/_MetaBasicCMA ssetCache_/Assets/Articles/DDGEngagementfull.pdf

Vazirani, N., 2007. Employee Engagement. SIES College of Management Studies, Nerul. http://www.siescoms.edu/images/employee_engag ement.pdf 